\title{
EVALUATION OF CHOSEN PARAMETERS OF SERVOMECHANISMS
}

\author{
Natália GECEJOVÁ, Marek ČEŠKOVIČ*, Pavol KURDEL \\ Technical University of Košice, Faculty of Aeronautics, Department of Avionics, Rampová 7, 04121 \\ Košice \\ *Corresponding author. E-mail: marek.ceskovic@tuke.sk
}

\begin{abstract}
This paper provides a comprehensive view of the issues in the field of servomechanisms of unmanned aircraft, which are used in the Department of Avionics for both education and research purposes. This contribution will describe the methodology and individual measuring devices, facilitating the control of prescribed parameters with parameters measured in real conditions. As some manufacturers deliberately exaggerate the data of their products to compete with other manufacturers, it is important to have a proven and reliable method for the evaluation of these parameters. The last part provided the results of control measurements of the selected servomechanism.
\end{abstract}

Keywords: measurement; methodology; servomechanism

\section{INTRODUCTION}

With the expansion of unmanned aircraft at hobby airports, but also in everyday life, it was necessary to capture their use not only by legislative but also with regard to the components used. A constant increase of safety in every aspect is essential, so misleading manufacturers' data can affect the performance of the flight or aircraft and thus the safety of the flight. Furthermore, early verification of the parameters of servomechanisms before installing them into the aircraft can prevent possible further damage $[1,2]$.

Following the failure rate of the servos, but also the possibility of comparing the table parameters given by the manufacturer, the methodology of verifying the parameters together with the design of the measuring workplace will be described. The created workplace is capable of experimental verification of individual servos' parameters and comparing them with the given (desired) values $[2,3]$.

\section{POSSIBLE FAILURES OF SERVOMECHANISMS}

The number of components from which the servo is designed is subject to wear, constant mechanical and thermal stress - proportionally, the probability of failure of individual parts and ultimately the servo as a whole increase.

The causes of a failure are conditions, phenomena or actions that cause or accelerate the mechanism of the failure. It can be:

- External cause of the fault - here belongs classify the adverse effects of the environment, humidity, exposure to excessive temperatures or, conversely, low operating temperatures.

- Internal cause of failure - adverse effects during production and assembly, poor-quality components, unsuitable construction, unreasonable load [4,5].

Thus, a failure can be understood as a loss of the system's ability to perform the required functions under predefined technical conditions. Therefore, it is inconceivable that the technical data on the servos provided by the manufacturer does not correspond to reality and thus endanger the operation of the entire electronic system of the aircraft. 
There are only two options when a servo fault is detected. The first is to identify the damaged component and, if spare parts are available, to replace the damaged parts. This solution can be applied mainly to gearing, servo-electric motor, but only in rare cases to a printed circuit board with electronic circuits.

Therefore, the second option is the more preferred option. This is the replacement of the servo piece by piece. Whether the servo is replaced by the same type or a different servo is applied, but with the same parameters, depends on the specific case - for example, it is advantageous for a wing that uses two or more servos to control the control surface to replace the same type of servo. This ensures the best possible synchronization with each other.

\subsection{Methodology of measuring servo parameters}

The parameters selected for control measurements were selected based on technical tables provided by the servo manufacturers. Their verification will provide a comprehensive picture of a particular servo and answer whether the given technical specifications are identical to reality. Thanks to this, it can be determined whether the given servo is suitable for the selected application or whether the manufacturer provides misleading data. These are the ones that can cause an unmanned vehicle mission failure, loss of control or even crash.

Servos with deceptive stated parameters can even cause significant damage to property or human health. These facts make it clear why a thorough inspection of servomechanisms and verification of technical parameters is necessary. Subsequently, that offers ample opportunities to improve quality, accuracy and measurement methodology.

\section{HITEC D625MW SERVOMECHANISM MEASUREMENT}

The selection of the servo for testing was targeted, as this servo will be implemented in a new unmanned aircraft obtained for the needs of the Department of Avionics, Faculty of Aeronautics Technical University of Košice, after successful testing. It is a sport acrobatic upper-wing aircraft, Carbon Cub from the company Hangar 9, with a wingspan of $2280 \mathrm{~mm}$ and estimated take-off weight of $5.2 \mathrm{~kg}$. This aircraft will be used as new testbed for testing new sensors, autoflight solutions and new approaches to control algorithms using neural networks [6].

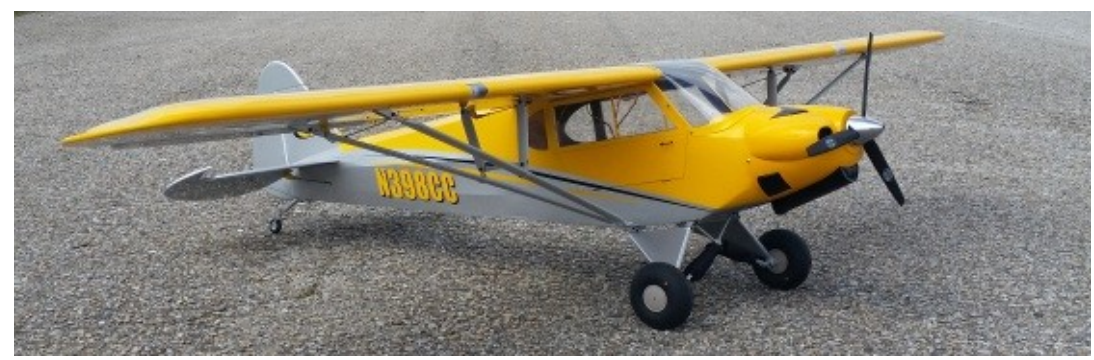

Figure 1 Model of the aircraft Carbon Cub 15cc by Hangar 9 [7]

\subsection{Parameters of the tested servo}

The technical parameters of the aircraft model provided the basis for a specific choice of the servo. A programmable digital servo with ultra-fast response, accuracy and a resolution of 4096 steps was selected. It is equipped with a 32-bit processor and a 12-bit AD (Analog-to-digital) converter, thanks to which this servo differs significantly from previous models.

The servo can be programmed using the universal servo-programmer Hitec DPC-11, which supports the PC interface. The following parameters can be set using this programmer:

- dead bandwidth in ten steps,

- sense of rotation,

- rotation speed, 
- soft start,

- neutral,

- amount of deviation up to $180^{\circ}$,

- fail-safe mode on/off,

- overload protection by power limitation in the interval of $0 \%$ to $50 \%$,

- reset to factory default settings,

- output shaft with 25-tooth polygon carrier [4,5].

The advantage of this servo is the possibility of its supply from batteries with a higher nominal voltage, in the range of $4.8 \mathrm{~V}$ to $7.4 \mathrm{~V}$ - depending on the required thrust and speed of the servo, which depends on the supply voltage. It follows that the servos can be powered directly from a 4 to 6 cell $\mathrm{NiMH}$ or NiCd battery, a double-cell Li-Fe, Li-Pol or Li-ion battery. The range of these voltages is called "Wide Voltage" for Hitec servos.

The servo has all-metal gears, the output shaft is mounted in two ball bearings and is intended for use in RC aircraft models up to $5.5 \mathrm{~kg}$ and $\mathrm{RC}$ cars in $1: 10$ or $1: 18$ scale $[4,8]$.
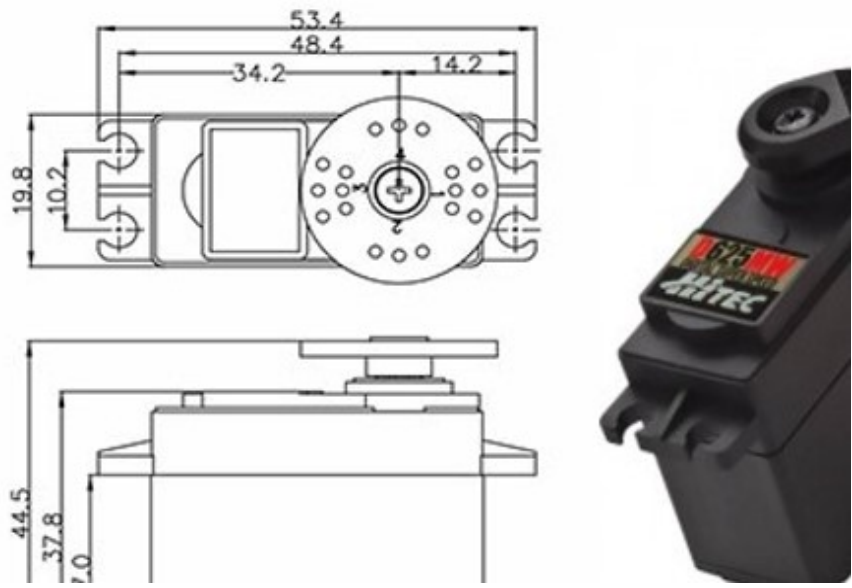

Figure 2 Technical drawing and visualisation of the tested Hitec D625MW servo [9]

\subsection{Speed measurement}

For the most accurate evaluation of the results of measuring the speed of the tested servo, two independent methods were chosen - determining the speed through a video camera and measuring with the help of a Jetibox [10].

These two methods will be discussed in the following paragraphs.

The temperature of the room in which the measurement took place reached $21^{\circ} \mathrm{C}$. There were ten cyclic repetitions of the measurements, with approximately five-second breaks. The supply voltage was stabilized and corresponded to $7.4 \mathrm{~V}$. Data recording was a digital - video camera backed up by visual reading and manual recording of displayed data.

The direct connection of the Jetibox to the servo enabled cyclic repetition of measurements with the required angular deviation of $60^{\circ}$. For the parameters defined in this way, i.e., the nominal voltage $7.4 \mathrm{~V}$ and the angular deviation of $60^{\circ}$, the manufacturer set the servo speed to be $0.13 \mathrm{~s} / 60^{\circ}$, which can be verified in the table supplied by the manufacturer - Table 1 .

In addition to comparing the speed given by the manufacturer and the actual values, this measurement aimed to compare the accuracy of the individual measurement methods.

\subsubsection{Speed measurement using video camera}

The SJcam SJ4000 wide-angle camera was used to measure speed, which allowed setting sixty frames per second. This facilitated the final video analysis in the AVIdemux program, which allowed the viewing of individually captured images. 
Based on the time track of the video, it was possible to determine the exact time at which the extended servo lever indicator was in the extreme positions, defining the upper and lower limits of the $60^{\circ}$ angular deviation. A table and the resulting graph of the partial measurement were compiled from the obtained data.

Table 1 Technical data table of the tested servo D625MW specified by the manufacturer [4,9]

\begin{tabular}{|l|l|}
\hline Size of servo & standard \\
\hline Type of servo & digital \\
\hline Thrust - voltage $4.8 \mathrm{~V}[\mathrm{~kg} / \mathrm{cm}]$ & 6.30 \\
\hline Thrust - voltage $6.0 \mathrm{~V}[\mathrm{~kg} / \mathrm{cm}]$ & 8.80 \\
\hline Thrust - voltage $7.4 \mathrm{~V}[\mathrm{~kg} / \mathrm{cm}]$ & 10.0 \\
\hline Speed - voltage $4.8 \mathrm{~V}\left[\mathrm{~s} / 60^{\circ}\right]$ & 0.20 \\
\hline Speed - voltage $6.0 \mathrm{~V}\left[\mathrm{~s} / 60^{\circ}\right]$ & 0.15 \\
\hline Speed - voltage $7.4 \mathrm{~V}\left[\mathrm{~s} / 60^{\circ}\right]$ & 0.13 \\
\hline
\end{tabular}

Table 2 Hitec D625MW servo speed values (measured)

\begin{tabular}{|c|c|c|}
\hline Measurement number & Speed (video camera) [s] & Speed (Jetibox) [s] \\
\hline 1. & 0.183 & 0.116 \\
\hline 2. & 0.183 & 0.116 \\
\hline 3. & 0.183 & 0.113 \\
\hline 4. & 0.183 & 0.115 \\
\hline 5. & 0.184 & 0.116 \\
\hline 6. & 0.183 & 0.114 \\
\hline 7. & 0.184 & 0.116 \\
\hline 8. & 0.183 & 0.116 \\
\hline 9. & 0.183 & 0.116 \\
\hline 10. & 0.184 & 0.114 \\
\hline
\end{tabular}

The tables (Table 1 and Table 2) shows that the difference in speed recorded by the video camera was almost insignificant, in the order of a thousandth of a second.

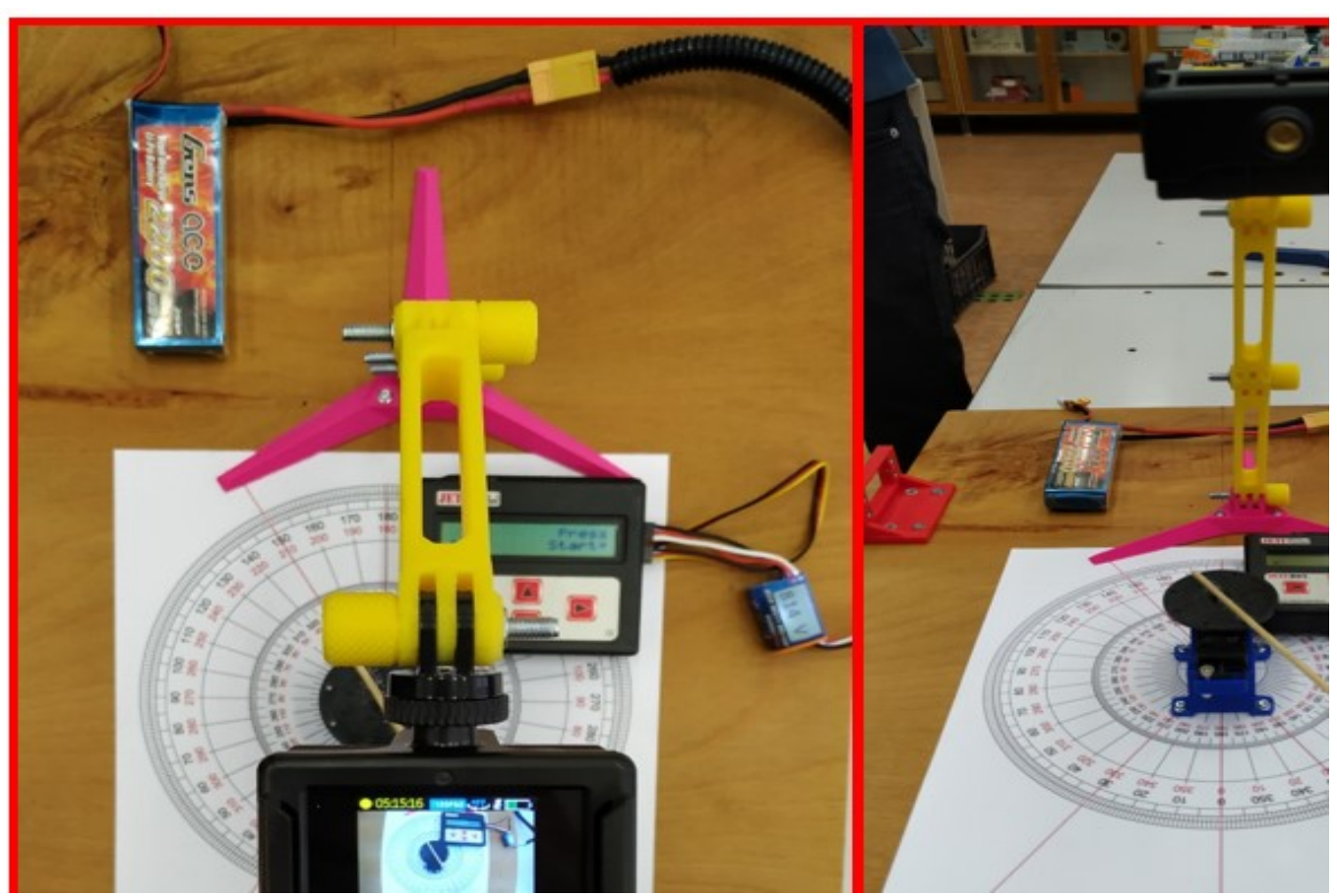

Figure 3 Measuring workplace for measuring speed 
From the graphic course, it can be read that the lowest measured speed of the servo had a value of $0.183 \mathrm{~s}$, and the highest reached $0.184 \mathrm{~s}$. According to this measurement, the tested servo does not meet the technical parameters for speed at a given voltage specified by the manufacturer. The deviation from the setpoint is in the interval $(0.053-0.054)$ seconds.

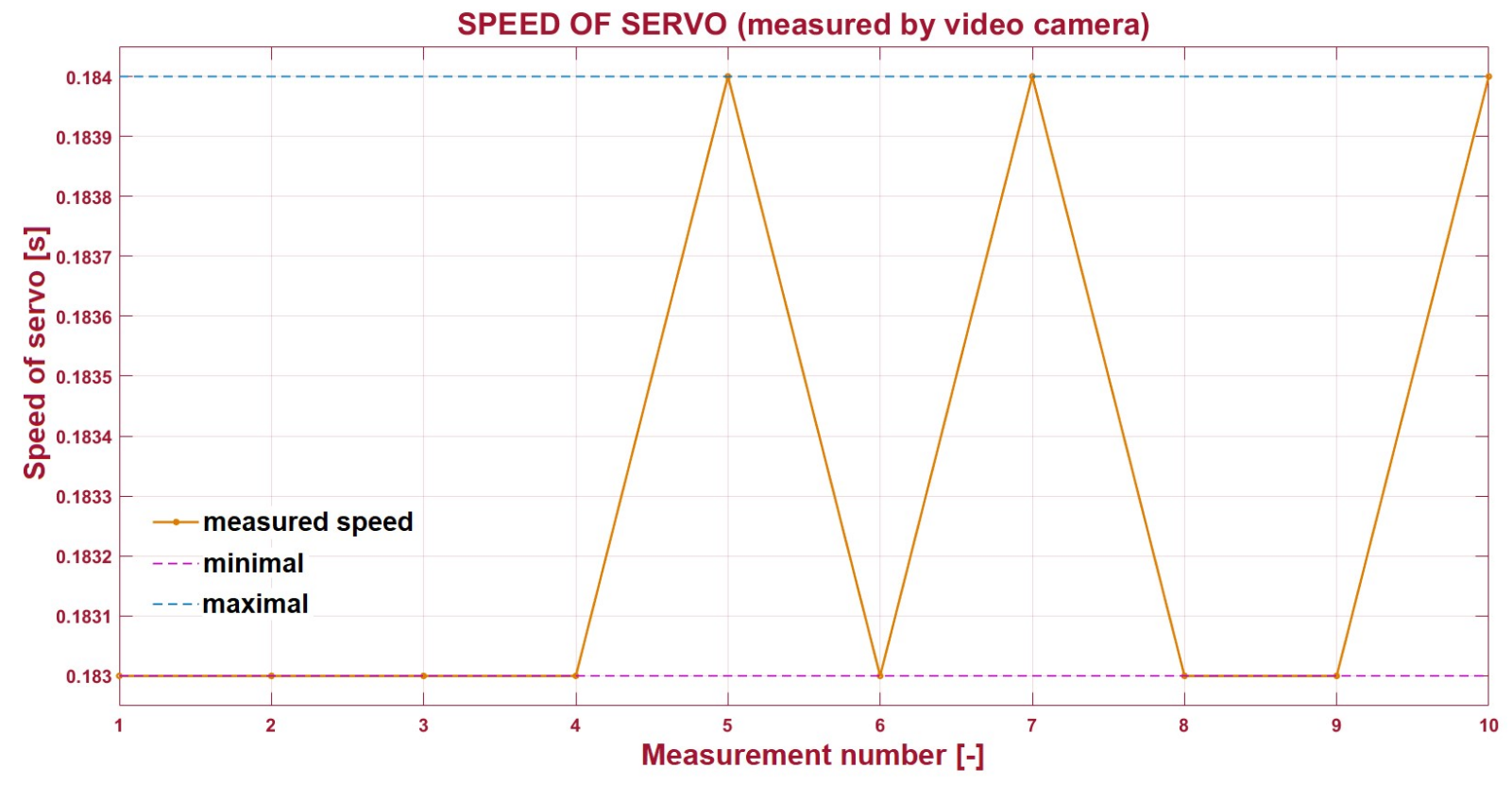

Figure 4 Graph of servo speed (measured by a video camera)

\subsubsection{Speed measurement using Jetibox}

Jetibox speed monitoring was chosen as a comparison method to the visual method. The direct connection of the Jetibox with the servo enabled its control and the ability to provide immediate information about the speed of its passage through the two extreme positions.

The primary setting that needed to be made on the Jetibox was to align the extreme positions marked on the protractors with the axis of the extended lever located on the servo. This was done by a digital trim, which represented the value of the PWM (Pulse Width Modulation) signal. After that, the recalculation of the distance travelled and the speed is performed automatically by the Jetibox via negative feedback.

As shown in the table of measured values (Table 2), the values obtained by this measurement method also showed only minor deviations, in the order of a thousandth of a second. However, the measured data came closer to the data declared by the manufacturers.

\subsubsection{Comparison of measurement methods}

The difference in the measurement results is significant - optical measurements with a video camera showed relatively large differences in the measured speed and the speed declared by the manufacturer.

Despite the methodological procedures for both types of measurements, there were significant differences in the results. Although the individual measurements showed only small deviations, a difference of up to seven-hundredths of a second is evident when comparing them.

On the other hand, the measurement with a video camera, Figure 5, represented by a purple curve, which initially seemed less accurate, showed almost constant values of the transition time between the extreme positions throughout the measurement. These values can be considered relevant, as the 
camcorder's setting of sixty frames per second made it possible to accurately target the initial movement of the servo lever, as well as to calculate its oscillation.

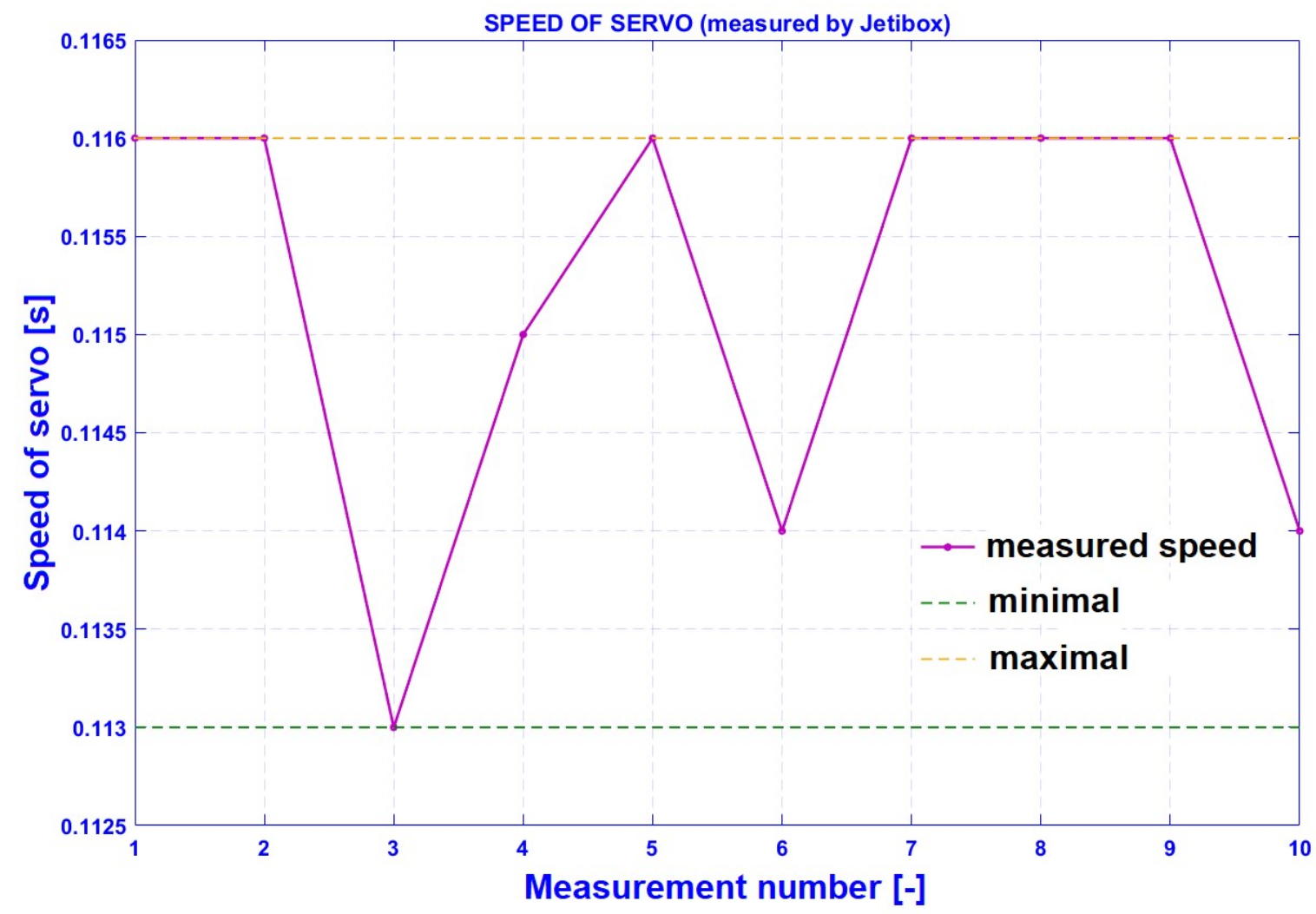

Figure 5 Graph of servo speed (measured by a Jetibox)

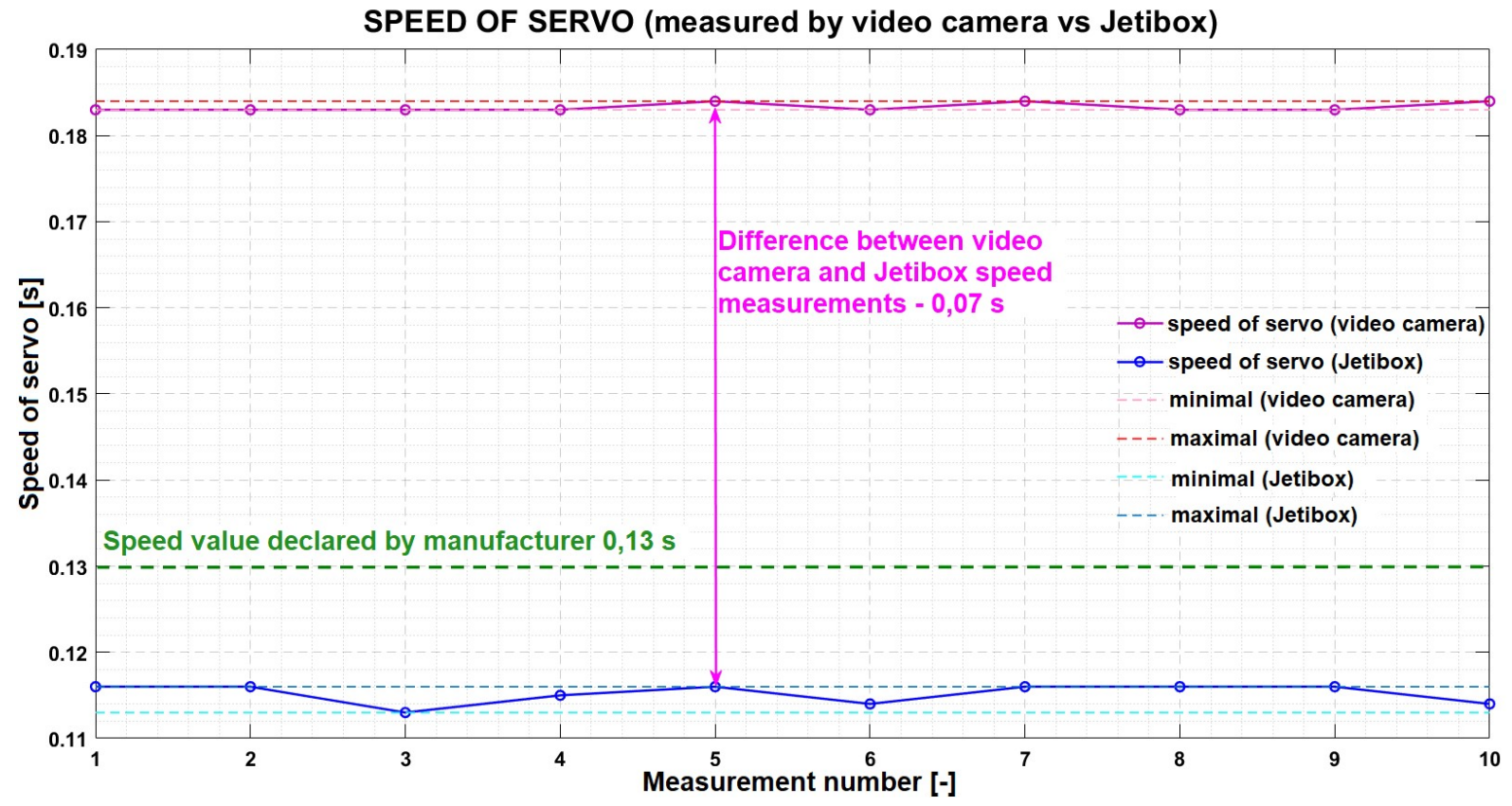

Figure 6 Graphical comparison of servo speed measured by individual methods 
Thanks to the video analysis program, which allowed the selection of an image with the servo lever's initial movement and final travel and the storage of an exact time track, it facilitated the calculation of the value of the transition between the specified extreme positions.

It follows from the above that the tested servo does not meet the prescribed requirements for the speed of movement by $60^{\circ}$ at a voltage of $7.4 \mathrm{~V}$. It can also be stated that the method of measuring speed with a video camera proved more reliable than the digital method of measuring Jetibox - with predefined PWM signal width.

\subsection{Measurement of thrust and holding torque}

Thrust measurement is characterized by the need to accurately recalculate the test load to a lever of a suitably selected size, which is mounted on the tested servomechanism. In our case, a $5 \mathrm{~cm}$ long lever was mounted on the servo shaft. At a given thrust of $10 \mathrm{~kg}$ per $1 \mathrm{~cm}$ of the lever, it can be determined by a simple calculation described in the methodology of this measurement that when using a $5 \mathrm{~cm}$ lever, the servo thrust of $0.625 \mathrm{~kg}$, i.e. $625 \mathrm{~g}$, is given after recalculation.

As well as testing the servo speed, this measurement took place in a room with a constant temperature of $21^{\circ} \mathrm{C}$ and a supply voltage of $7.4 \mathrm{~V}$ was used. The servo was blow-cooled during the measurement. The number of cycles performed without breaks was set at fifty repetitions at a steady load.

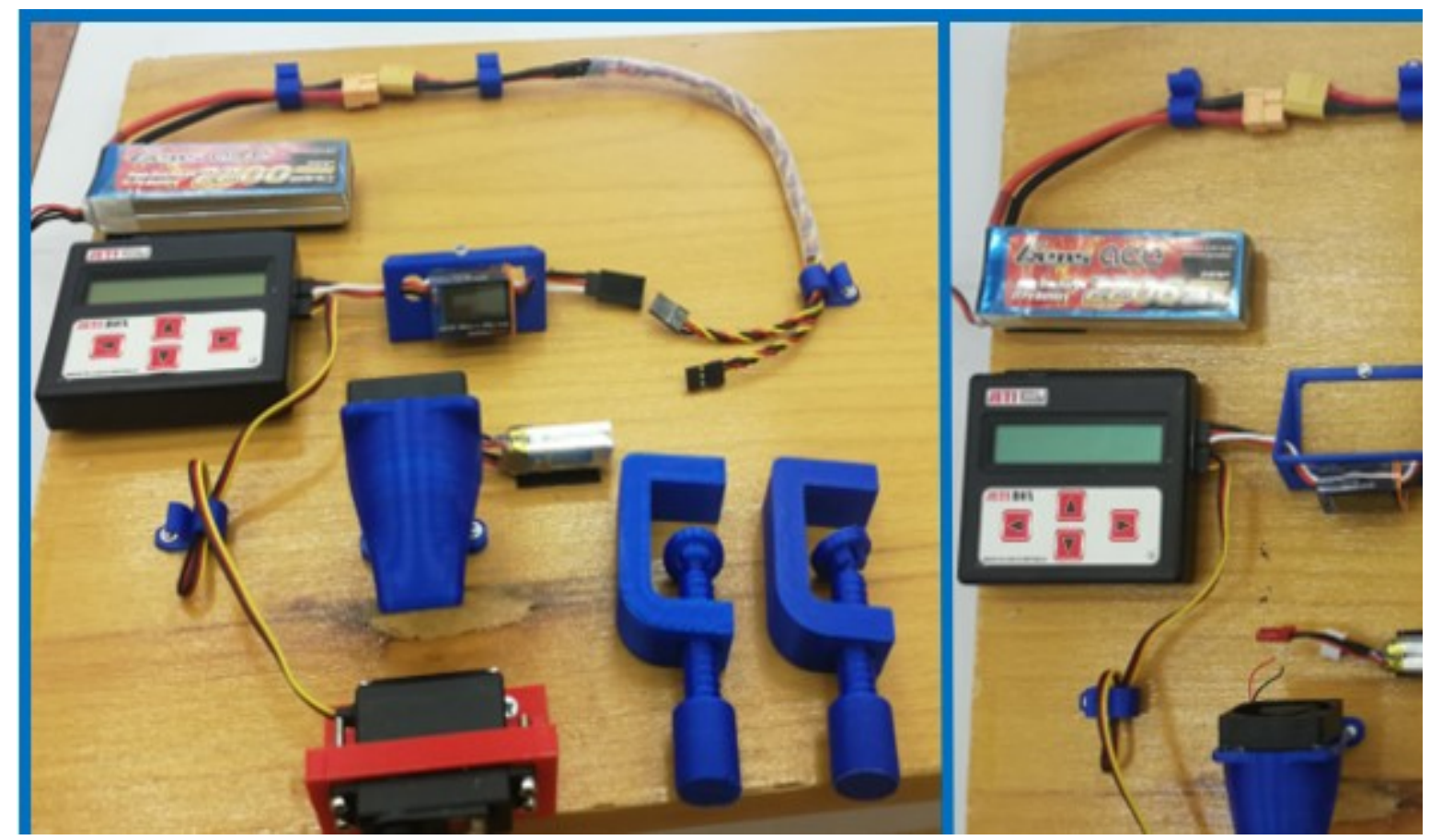

Figure 7 Measuring station for measuring thrust and holding torque. The tested servo is mounted in red frame.

In this case, the Jetibox was again used to control the servo, this time, and the cycling function was chosen - used in particular when running the servos. It allows setting the number of repetitions, the amount of deviation, and the speed. The speed was chosen based on the initial attempts, which best resulted in a setting of $\mathrm{v}=25$. This corresponds to a change in the previous PWM signal value of $0.025 \mathrm{~ms}$. The pulse period is predefined to $20 \mathrm{~ms}$.

For a better understanding, can be given an example, where the speed $\mathrm{v}=1$ means that each subsequent pulse changes by $0.001 \mathrm{~ms}$ compared to the previous pulse until it reaches the specified value. The pulse period is also $20 \mathrm{~ms}$ in this case. 
Similarly, the size of the servo deflection in $\mu$ s is selected in the Jetibox, in the range from $100 \mu \mathrm{s}$ to $500 \mu \mathrm{s}$, from a mean value of $1.5 \mathrm{~ms}$. In our setting, when the speed was set at $500 \mu \mathrm{s}$, the control pulse varied from $1000 \mathrm{~ms}$ to $2000 \mathrm{~ms}$, i.e., $1500 \pm 500 \mu \mathrm{s}$.

The following table shows the increase in load weight.

Table 3 Overview of load weights used in thrust testing

\begin{tabular}{|c|c|c|}
\hline Load weight $[\mathrm{g}]$ & The number of repetitions [-] & Evaluation \\
\hline 625 & 50 & $\checkmark$ \\
\hline 700 & 50 & $\checkmark$ \\
\hline 1000 & 50 & $\checkmark$ \\
\hline 1200 & 50 & $\checkmark$ \\
\hline 1300 & 35 & $\times$ \\
\hline
\end{tabular}

The presented data ensure that the tested servo almost twice exceeded the expected thrust under our conditions - on the $5 \mathrm{~cm}$ long lever, it was able to perform the prescribed number of cyclic repetitions even with a load of $1200 \mathrm{~g}$, i.e., $1.2 \mathrm{~kg}$.

With a constant increase in load was reached the limit of $1300 \mathrm{~g}$, at which the servo was able to perform only 35 cycles to a complete stop. After this repetition, the servo could not move again in the required angular range and at the required speed.

This measuring station was also used to measure the holding torque of the servo. This is a measurement where the load increases until the servo lever relaxes and lowers due to gravity downwards. Again, it is important to move the servo lever to a horizontal position for this measurement - this is made possible by the connected Jetibox.

Empirical testing has shown that the Hitec D625MW servo was able to exceed the moment of force of a body weighing $3170 \mathrm{~g}$, i.e., $3.17 \mathrm{~kg}$, with a stabilized voltage source at $7.4 \mathrm{~V}$. The current consumption at the moment, when the most significant moment of force acted on the lever, was $1.8 \mathrm{~A}$.

In this case, it can be considered that the provided data about the tested servo is reliable. When measuring thrust, it can be discussed increasing the value compared to the expected reference value.

\section{CONCLUSION}

This paper deals with the design and comparison of servo testing methodology, which can be used in the whole spectrum of activities, whether unmanned aircraft, mechanical engineering, or robotics. The requirements for the quality and accuracy of servos differ from the chosen application. For the reliable operation of an unmanned flying vehicle, the safety requirements must be as high as possible this is an area where there is very little room for compromise and any effort to save or ease. Low demands and excessive compromises can cause considerable damage.

The necessary need to test all equipment and devices in the unmanned aerial vehicles sector, used in teaching and writing final theses at the Department of Avionics, Technical University of Košice, is related to ensuring flight safety.

The described measurements were performed according to the methodology outlined in work with the help of a measuring workplace, created according to CAD (Computer Aided Design) visualization and realized through $3 \mathrm{D}$ printing. It has been proven that for evaluation purposes, different methods should be used, as there was a significant difference of measured parameters like those shown in Chapter 3.

The challenge for the future is to try to test the servo in almost real conditions. This means that the signal for the servo will be used from the available flight data of the desired unmanned aerial vehicle (UAV). Such a measurement will get us even "closer to the onboard" and allow us to "replay" the flight directly in the measuring laboratory [11]. 


\section{References}

[1] Černý, M. Everything about servos (Czech original: Všechno o servech). From series of topics about RC models servos. 2015.2 Available at: https://www.horejsi.cz/Pages/ListClanky.aspx\#kapitola2

[2] Havlíček, V. Electric circuits 1 (Czech original: Elektrické obvody I.). Praha: ČVUT. 2014. 290 p. (Original in Czech language)

[3] Paláček, J. Can you choose the right servo?. (Czech original: Umite si vybrat správné servo?). Available at: http://www.jpmodels.cz/tipy-navody/

[4] Pelikán, D. Servos (Czech original: Serva). 2018. Available at: http://www.pelikandaniel.com/?sec=page \&id=22

[5] Dumea, R. Servos 101. 2018 Available at: https://www.flitetest.com/articles/servos-101

[6] Schrötter, M., - Bréda, R., - Andoga, R., - Főző, L. The evolution of the aircraft electric power systems. In: 2018 International IEEE Conference and Workshop in Óbuda on Electrical and Power Engineering (CANDO-EPE), 2018, pp. 159-162.

[7] Image copyright: Author's archive

[8] Tooley, M. - Wyatt, D. Aircraft Electrical and Electronic Systems: Principles, Operation and Maintenance. 2009. $438 \mathrm{p}$.

[9] Image copyright: https://htmodel.sk/servo-hitec-d625mw-1hi38801/

[10] Akagi, T. - Dohta, S. - Kobayashi, W. - Harada, S. - Koga K. Improvement of dynamic characteristics of low-cost servo valve using buckled tubes and RC servo motor. In: 2017 International Conference on Robotics and Automation Sciences (ICRAS), 2017, pp. 71-75, doi: 10.1109/ICRAS.2017.8071919.

[11] DC Servo Motor Parameter Estimation. 2019. Available at: https://uk.mathworks.com/help/sldo/examples/dc-servo-motor-parameterestimation.html? fbclid=IwAR24TidgArCt1Kyn9MjjiGgrxdmuJlLrbGp0quXkMkpSVhXgQftCZgDh9A

Received 12, 2021, accepted 12, 2021

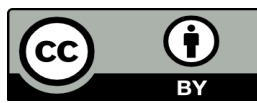

Article is licensed under a Creative Commons Attribution 4.0 International License 